\title{
A Study of Flow Structure Topology in the Vicinity of a Concave Bed Sill Using Numerical Model
}

\author{
Moslem Sohrabi $^{1, ~ *}$, Alireza Keshavarzi ${ }^{1,2}$, Mahmood Javan ${ }^{1}$ \\ ${ }^{1}$ Water Engineering Department, Shiraz University, Shiraz, Iran \\ ${ }^{2}$ Center for Infrastructure Engineering, Western Sydney University, Penrith, Australia
}

Email address:

Moslem.sohrabi@gmail.com (M. Sohrabi)

${ }^{*}$ Corresponding author

\section{To cite this article:}

Moslem Sohrabi, Alireza Keshavarzi, Mahmood Javan. A Study of Flow Structure Topology in the Vicinity of a Concave Bed Sill Using Numerical Model. Hydrology. Vol. 8, No. 2, 2020, pp. 26-33. doi: 10.11648/j.hyd.20200802.12

Received: August 10, 2020; Accepted: August 22, 2020; Published: August 31, 2020

\begin{abstract}
Stabilization of the banks and bed of the river is an important problem in river engineering works. River bed scouring is a major environmental problem for fish and aquatic habitat resources. Using a bed sill is one approach that can be used to prevent waterway bed scouring. In this study, a concave bed sill was tested in an experimental program with movable bed condition. In addition to the experimental program, numerical simulations were undertaken to explore the flow characteristic around concave bed sill. In experiment the results showed that most scouring occurred at the channel sides, while deposition occurred in the middle of channel downstream of the concave bed sill. During the experiment two dimensional flow velocity was measured using particle image velocimetry (PIV). It was found that a vortex formed at the sides and downstream of the concave bed sill and then stretched to the middle of the channel. The results also indicated that there was minimum flow vorticity intensity at the center of the channel where deposition occurred. The numerical results were compared with this experimental data to validate the numerical simulations. The numerical results confirmed that for a concave bed sill, similarly a vortex formed at the side of the channel which created the maximum scouring depth at the side wall and with following deposition of sediment particles in the centerline of the channel.
\end{abstract}

Keywords: River Engineering, Concave Bed Sill, Scour, Numerical Model, Vortex

\section{Introduction}

One of the consequences of the erosive action of flowing water on the bed and banks of alluvial river is scouring. The scouring of sediment particles from the bed and banks of a river creates problem in natural and artificial channels. In contrast, the deposition of sediment particles produces riverine habitat problems too.

Using bed sill is one of the most beneficial methods for prevention of scouring in the river bed $([1,4])$. Some studies were also made on bed scouring downstream of linear bed sill constructed at right angle to flow direction and under different flow conditions by $[4,3,12,15]$. In these studies it was found that the maximum scouring created uniformly in transverse direction at downstream of a linear bed sill. A study was made on bed scouring downstream of multiple bed sills with different horizontal distances in steep slope, and they found a non-linear regression relationship to determine maximum depth of scouring by [2]. Tested nine different models of bed sill including linear with right angle to flow direction, convex, concave and tilted were installed to the flow direction [9]. They measured bed scouring at the downstream of the bed sills and showed that concave pattern dramatically reduced bed scouring at the center line of the channel; whereas convex pattern reduced bed scouring at the banks.

Predicted local scour under unsteady flow conditions was modeled by [16]. They demonstrated that scouring progress in unsteady flow can be done as a series of steady flow condition in different portions of the flood hydrograph.

Modelling of scouring depth around an arch-shaped bed sill was investigated by [11]. Their results showed that between the two mathematical models of ANN and ANFIS, the latter gave better estimations.

Three phases of scouring including initial, developing and equilibrium phases were modelled by [13].

A study was made on flow pattern and turbulence structures 
in a scour hole downstream of a submerged weir by [5]. According to their result, flow structures changed near the structure in downstream of submerged weir with a large vortex area and flow reattachment area are formed.

A study was showed that flow regimes over the weir are independent of the sediment size at the bed, and also flow regime can be defined as a function of upstream Froude number and weir height to tailwater depth ratio [6]. Some studies were showed the impact of shape and adjustment of bed sills on the bed and bank scouring at the downstream of the bed sills by [10, 14]. The measurement of bed scouring at the downstream of bed sills showed that the maximum amount of scouring at the bank of the channel occurred by concave bed sill whereas the convex bed sill had the maximum amount of scouring at the centreline of the channel. Furthermore, the stabilization of the bank and centre were observed at the downstream of wing shape and sine bed sills. The location of maximum depth of scouring depends on the shapes of the bed sills.

Bed sill was used as a countermeasure for reducing scour downstream of a rigid apron and observed that a bed sill positioned nearby downstream reduces local scouring by [7]. Tested a combination of bed sill and riprap as a countermeasure and obtained results obtained showed that this technique reduces maximum scour depths significantly [8].

Most of the previous studies have been done on experimental investigation of a linear bed sill with right angle to flow direction; however flow structure on concave bed sills remained unclear. Complicated flow structure of described flow structures around bed sills have directed to the focus on experimental investigation together with numerical analysis as one of the best ways for assessing of flow pattern. Therefore, a comprehensive experimental and numerical study was performed in this research work to find flow structures at the downstream of a concave bed sill installed at an erodible bed and results are presented herein.

\section{Materials and Methods}

\subsection{Experimental Setup}

An experimental test was performed in a rectangular flume with a mobile bed condition. The experimental flume had a length of $6 \mathrm{~m}$, a width of $0.25 \mathrm{~m}$, a height of $0.25 \mathrm{~m}$ and slope of 0.001 ; see Figure 1 for details. The bed and walls of the flume were made of glass for better visualization of the flow and bed scouring. The bed of the flume was covered by sand particles of approximately uniform size with a $D_{50}$ of 0.78 $\mathrm{mm}$. As can be seen from Figure 1, the concavity of the concave bed sills was placed in the flow direction with a radius of $\mathrm{T}=0.062 \mathrm{~m}$. A gate was installed at the downstream of the flume for the adjustment of flow depth and velocity.

The velocity data was measured by particle image velocimetry (PIV) with a frequency of $15 \mathrm{~Hz}$. The experimental tests were undertaken with a flow rate of $2.9 \mathrm{~L} / \mathrm{S}$. Two dimensional velocity fluctuations of flow over bed sill were measured in a horizontal plane. Measurements were made at five different sections from the wall to centerline. The PIV was employed to capture the two-phase flow field. The time interval between the two frames in a pair of images was 10 milliseconds, and the time interval between sequential frame pairs was $1 / 15$ second. The tracer particles were white Polyamid 2070 with sphere shape, diameter of $5 \mu \mathrm{m}$ and a specific gravity of 1.016. A dual Nd-YAG, $50 \mathrm{~mJ} /$ pulse laser, $532 \mathrm{~nm}$ wavelength was used to illuminate the flow field. The laser sheet, which was approximately $1 \mathrm{~mm}$ thick, was located at top of the flume at a distance above water surface. A high-resolution CCD camera (PCO-1600) was used to view the light sheet plane at right angle through the flume's Plexiglas wall and then to capture the picture frames. The capture images were $1600 \times 1200$ pixels size. The CCD camera was positioned at the side of flume and then the measurements were made at a flow field with domain view of $250 \times 110 \mathrm{~mm}$. The instantaneous images were processed using VidPIV-47XP-Beta software. The adaptive cross correlation was used to determine the average particle displacement within the interrogation area. The mean velocities and turbulent statistics presented subsequently were obtained using $32 \times 32$ pixels interrogation window with $50 \%$ overlap for 700 instantaneous image pairs. As a result, the flow velocity was measured at 8092 points within the flow field.

\subsection{Numerical Model}

In this part, the package software was used to calculate flow pattern. The topographical dimensions of scour were transferred to software after the scour was developed. Then model was imported package software in order to analyze the flow pattern around bed sill (Figure 2).

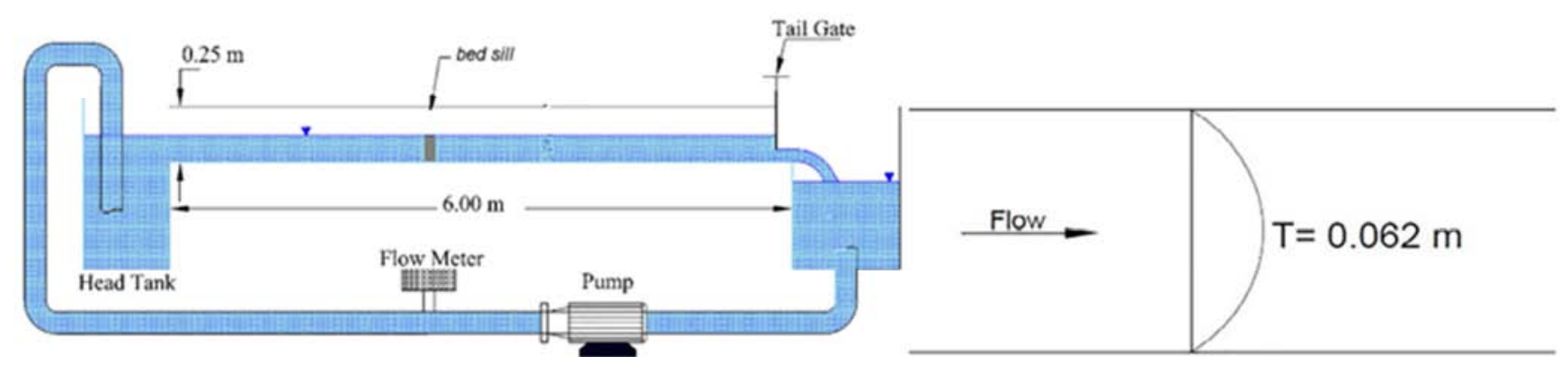

Figure 1. a) Schematic of the laboratory flume and b) Plan of non-linear bed sill installation. 


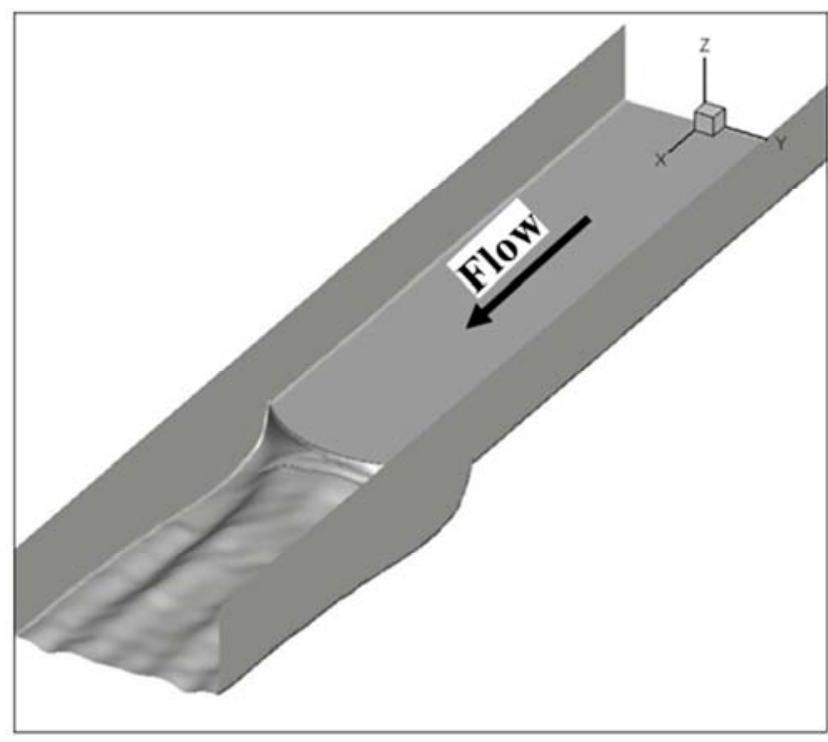

Figure 2. Three dimensional shape of model.
Table 1. Mesh analysis.

\begin{tabular}{lll}
\hline Simulation & Number of elements & Error (\%) \\
\hline 1 & 292779 & 22 \\
2 & 420306 & 15.79 \\
3 & 511443 & 6.02 \\
\hline
\end{tabular}

\subsection{Boundary Conditions and Mesh Study}

In order to prepare flow model geometry and mesh is used package software. Meanwhile to reduce computing time, only a part of the channel is simulated. The triangular unstructured meshing model geometry is used in this numerical simulation. As shown in Table 1, by increasing computing cells, error values are reduced and ultimately becomes constant. Finally, the number of the mesh was found to be 511443 triangular elements.

Boundary condition contains entrance section, output section, walls and free flow surface. The applied boundary condition has been shown in Figure 3. The inlet boundary is velocity inlet and the entrance velocities values are $0.147 \mathrm{~m} / \mathrm{s}$ and $0 \mathrm{~m} / \mathrm{s}$ for water and air, respectively.

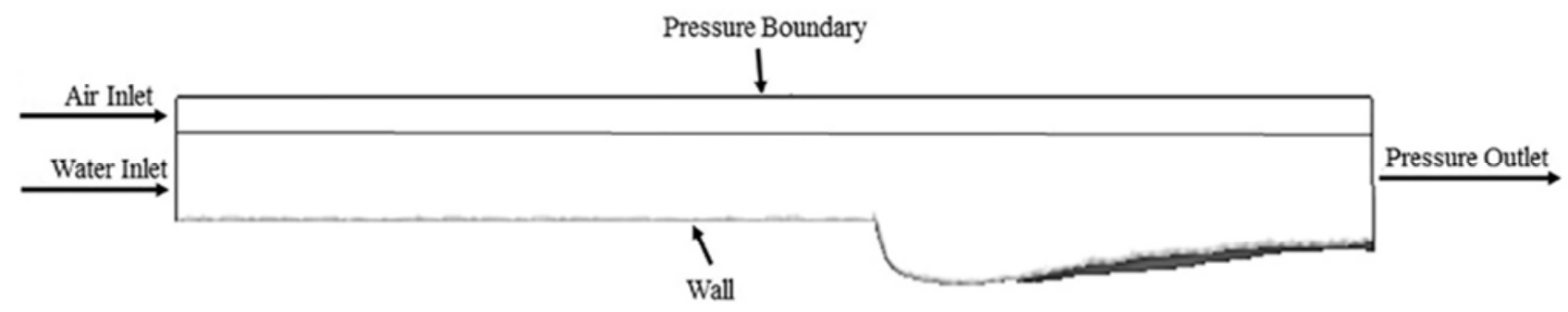

Figure 3. Boundary condition of simulation domain.

\section{Results and Discussion}

Experimental results showed that different vortices were created near the walls at the downstream of the bed sill. The vortices transport sediment grains to the centerline of bed sill. During the early stages of the experiment, scouring is low because of the absence of vortices. The scouring depth grows due to the increase of vortices intensity. The vortices strength reduces with distance from the walls through the downstream of canal. The maximum scouring depth occurred where the strongest vortex formed. The maximum scouring depth was found to be 0.047 meter (Figure 4).

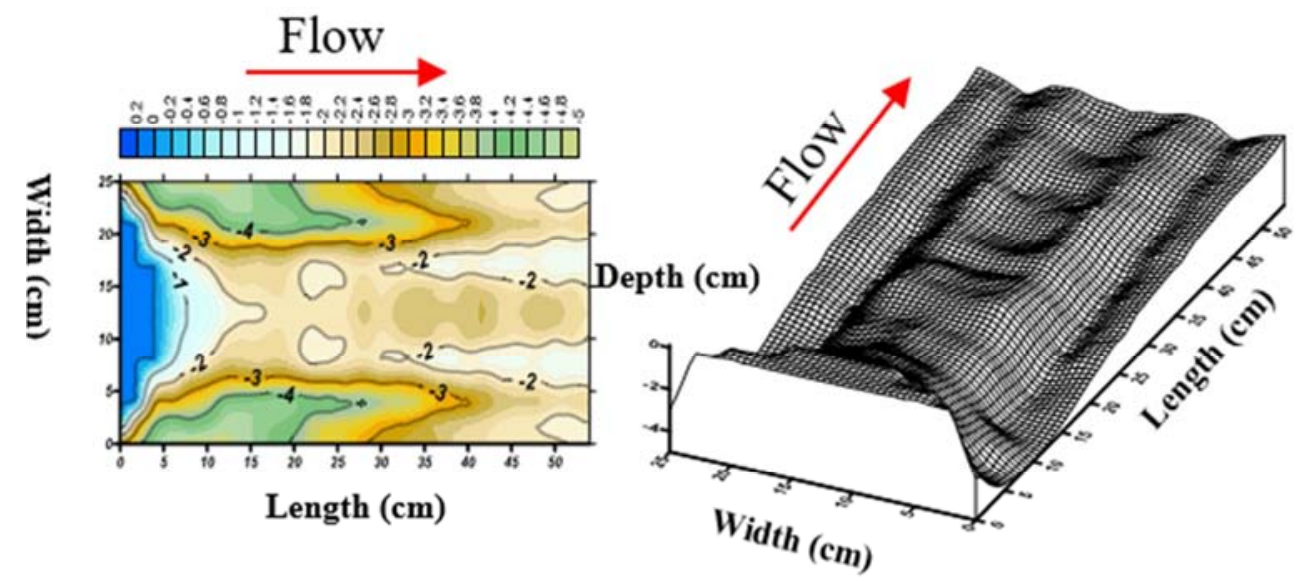

Figure 4. Three dimensional and contour lines plots of bed scouring.

Sections $\mathrm{A}$ to $\mathrm{C}$ that are shown in Figure 5 are longitudinal profiles for velocity measurement. The model in Figure 6 has 3 slices and hence the velocity contours are shown in 3 sections. As shown in Figure 6, by distancing from wall to the middle of channel, the negative velocity reduces. The flow separation zone size reduces to the downstream of bed sill by distancing from the wall. In some regions, the velocity is zero because of the stagnation point at the bed sill (Figure 6). The vortices near 
wall cause increase in scour depth at the bank more than centerline. Therefore, this is the reason why sediment particles moved from wall to the middle of the channel.

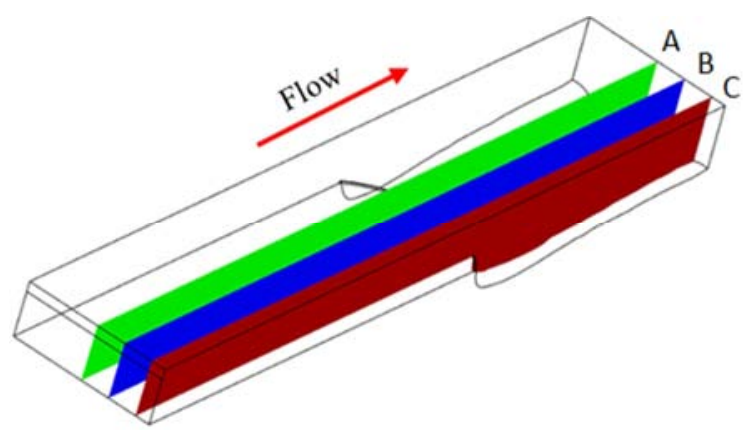

Figure 5. Section of A to C along $x$-direction.

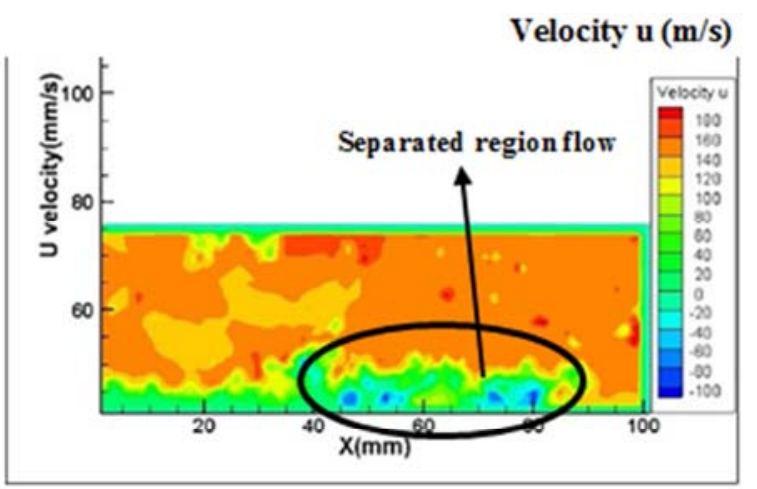

a) $0.02 \mathrm{~m}$ from wall

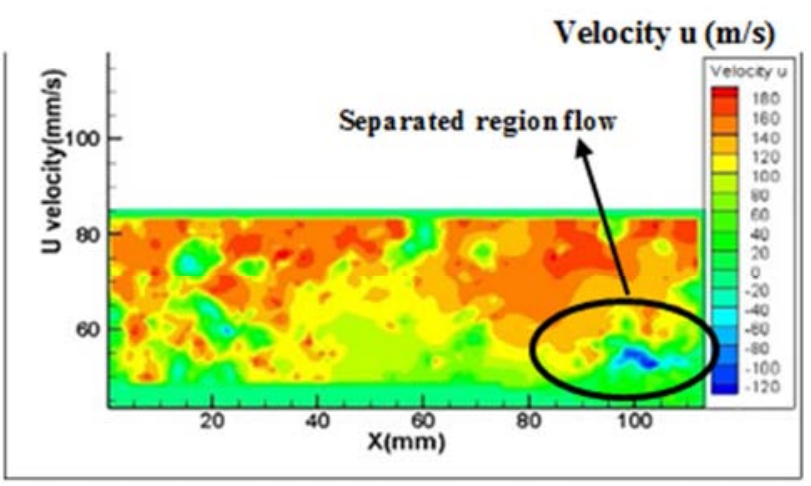

b) $0.1 \mathrm{~m}$ from wall

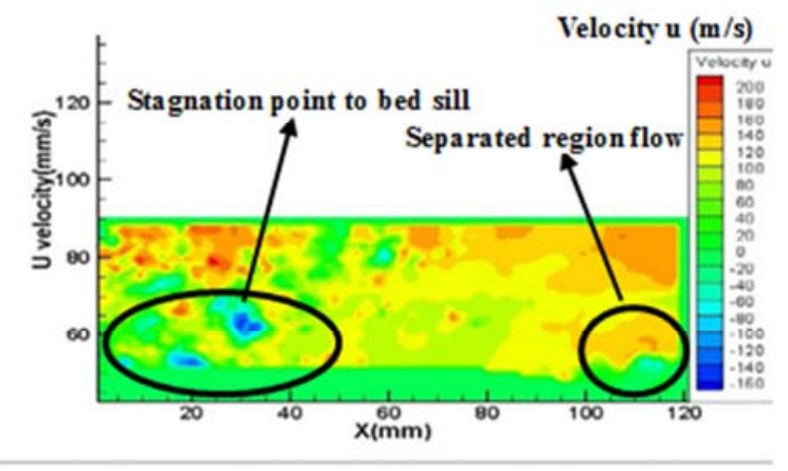

c) $0.125 \mathrm{~m}$ from wall

Figure 6. Flow velocity along $x$-direction (dimensions are in millimeters)
Figure 7 shows the vortex strength and streamlines in sections along $\mathrm{x}$-direction. As previously mentioned, the vortex strength reduces by increases of the distance from the walls toward the downstream of the channel. Besides, it was found that not only separation zone and negative velocity decrease by receding from wall but also the sediment particles were transported toward the center of the channel. By approaching to the middle of the channel, the velocity increases and it creates a pressure drop in the center of the channel. As it can be seen sediment particles are transported to the middle channel due to vortex's rotation. According to the streamlines patterns, separated zone reduced from walls to the middle of the channel. Near walls turbulences were increased due to the interference of the vortex with boundary layer. The scouring depth is proportional to the vorticity intensity. Therefore, maximum of scouring depth occurs at the maximum vorticity intensity.
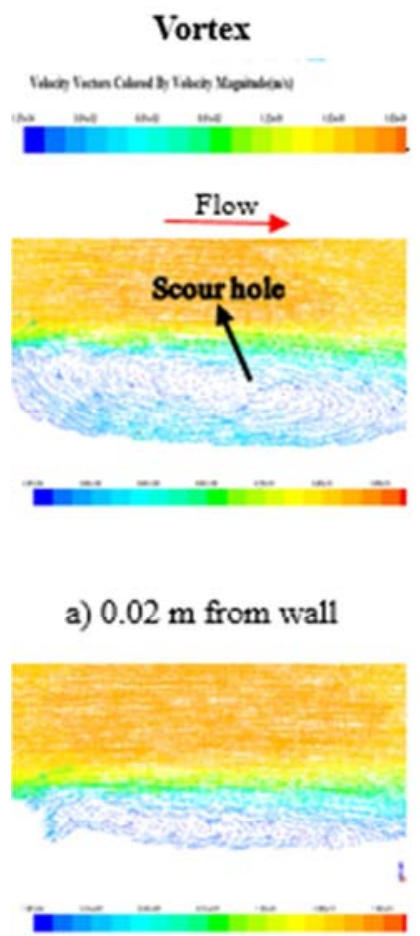

b) $0.075 \mathrm{~m}$ from wall

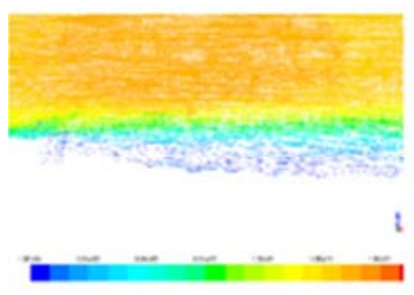

c) $0.125 \mathrm{~m}$ from wall a) $0.02 \mathrm{~m}$ from wall

\section{Streamline}

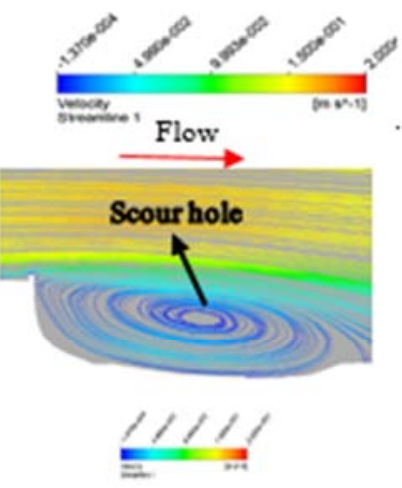

a) $0.02 \mathrm{~m}$ from wall

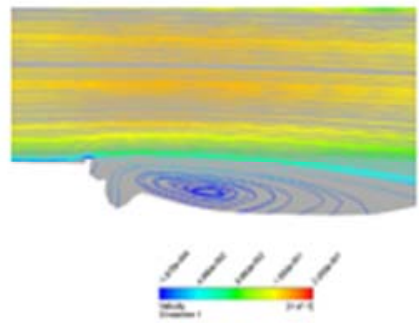

b) $0.075 \mathrm{~m}$ from wall

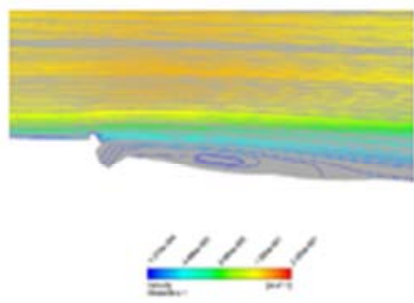

c) $0.125 \mathrm{~m}$ from wall
Figure 7. Velocity vectors and stream line along $x$-direction. 


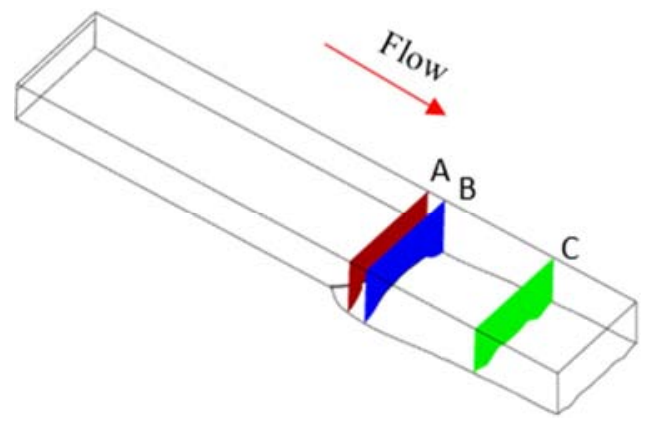

Figure 8. Section of A to C along y-direction.

View from side

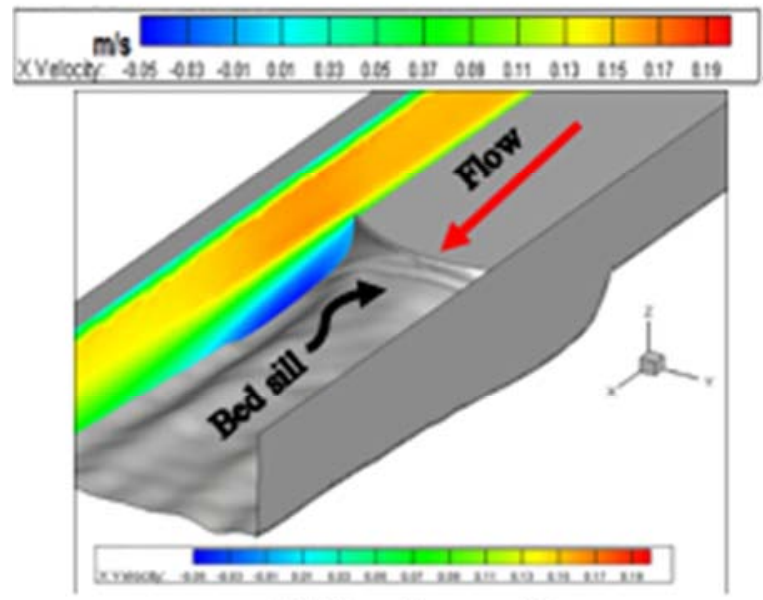

a) $0.02 \mathrm{~m}$ from wall

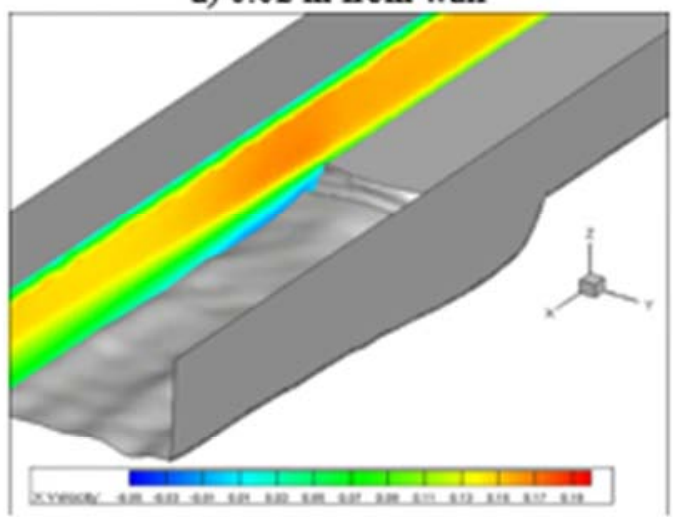

b) $0.075 \mathrm{~m}$ from wall

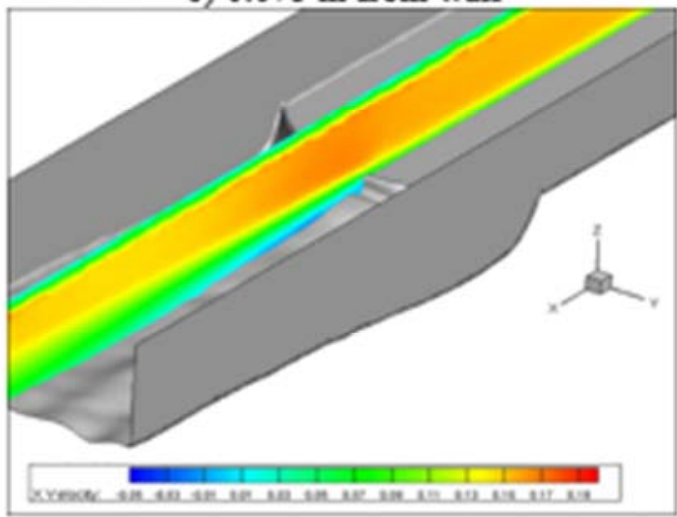

c) $0.125 \mathrm{~m}$ from wall

Figure 9. Contour lines of $x$-velocity from side view and front view.
View from front
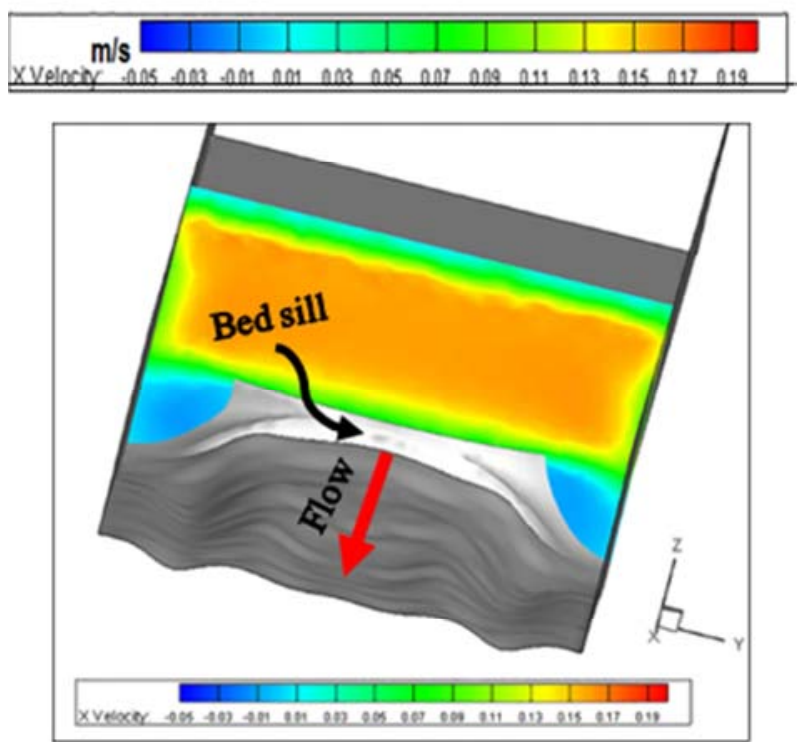

a) $0.04 \mathrm{~m}$ from bed sill

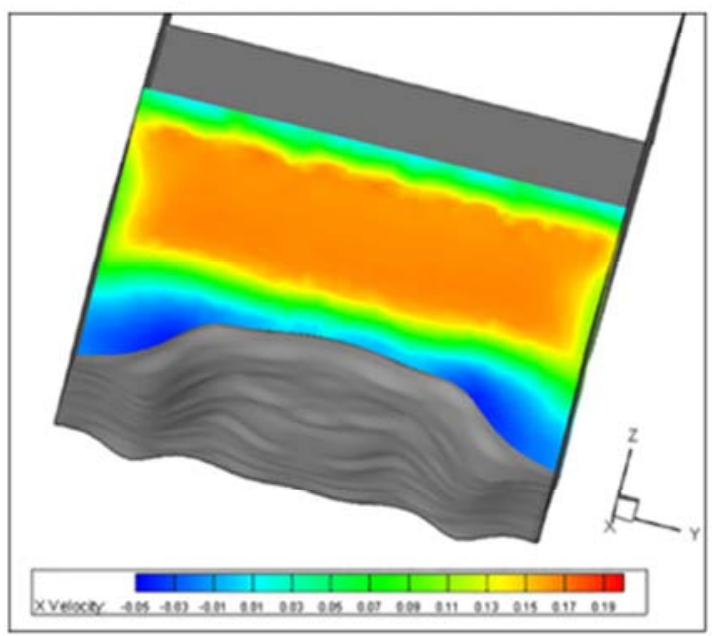

b) $0.08 \mathrm{~m}$ from bed sill

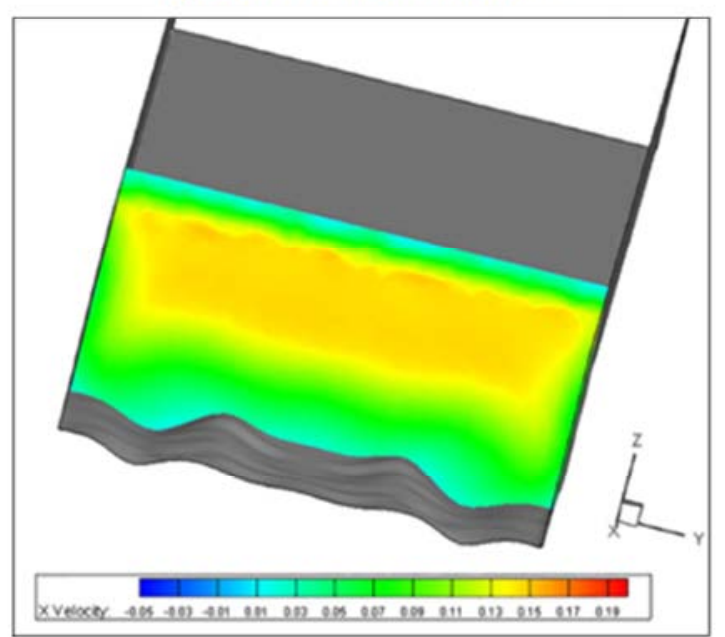

c) $0.34 \mathrm{~m}$ from bed sill

Figure 10. Contour lines of $x$-velocity from side view and front view. 


\section{Turbulent Kinetic Energy}

Turbulent Kinetic Energy: $\quad 0 \quad .0001 .0002 .0003 .0004 .0005 .0006 .0007 .0008 .000$ S $\left(m^{\wedge} 2 / s \wedge 2\right)$

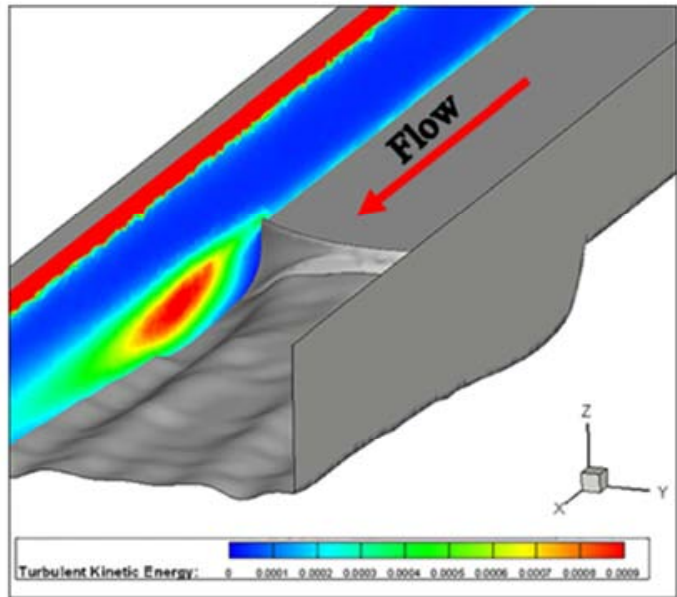

a) $0.02 \mathrm{~m}$ from wall

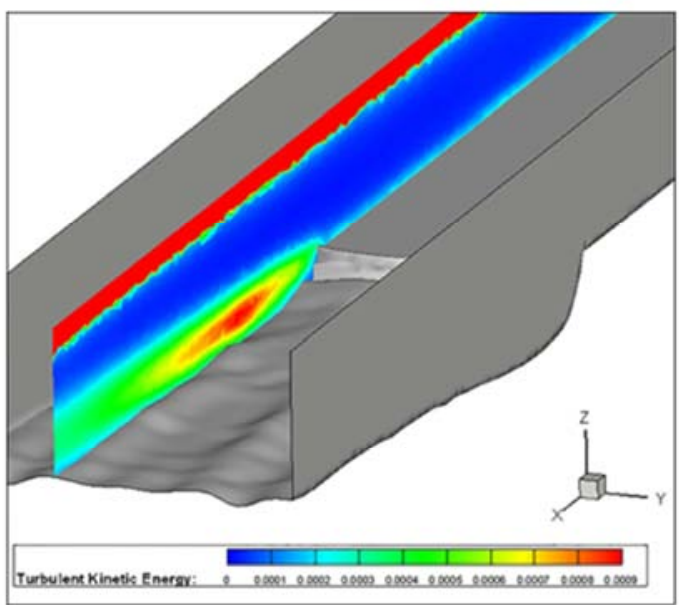

c) $0.075 \mathrm{~m}$ from wall

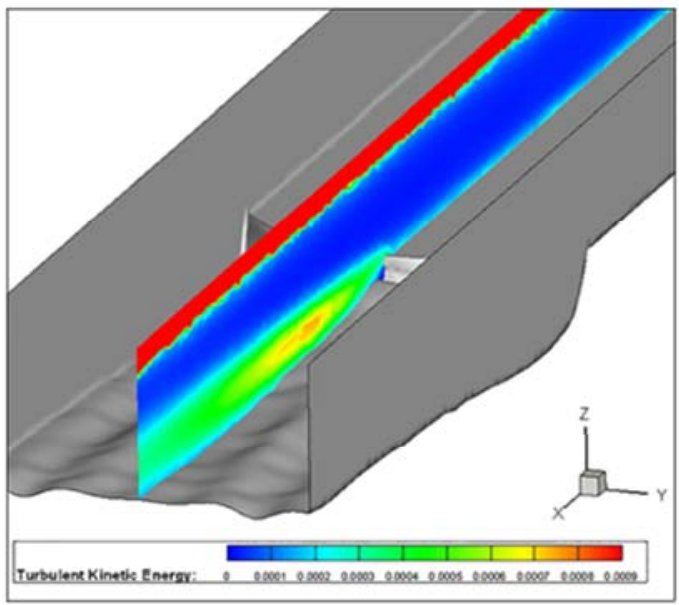

d) $0.125 \mathrm{~m}$ from wall
Figure 8 shows cross sections of $\mathrm{A}$ to $\mathrm{C}$ along y-direction. Figure 9 illustrates the Contour lines of $\mathrm{x}$ velocity from side view and front view in sections along $\mathrm{x}$ and $\mathrm{y}$ directions. According to Figure 9 negative velocity and separation zone increased alongside the wall. The more vorticity intensity alongside of the walls made the more scouring. According to Figure 10 separation zone increased from bed sill to downstream hence large vortex occurred at the maximum of scouring hole. Therefore, it is concluded that the vortex transferred from side walls to the center of the channel.

Figure 11 shows turbulent kinetic energy of the flow at the downstream of the bed sill. The magnitude of turbulent kinetic energy changes with velocity. Furthermore, the velocity near wall of model was smaller than the velocity in scouring hole. The maximum of turbulent kinetic energy occurred around the location of maximum scouring depth. Turbulent kinetic energy initiated a gradual increase from walls to the region of maximum scouring depth. Later it reduced due to the interference of vortex with boundary layer.

Figure 12 shows the velocity streamlines of simulated model. Direction of vortex motion was shown from sides to the middle of the channel and it decreased from bed sill to downstream.

\section{Comparison of Errors in Experimental and Numerical Models}

According to the experimental data and simulation results, the percentage of the error for each point of velocity profile is calculated. The percentage of error is listed in Table 2 and Figure 13. Figure 13 shows the comparison of experimental and simulated data of $\mathrm{x}$-velocity.

\section{Conclusion}

In this study, the flow pattern around the concave bed sill is presented. It was found that, the vortices created at the bank of the concave bed sill not only produced the maximum scouring depth at the sides of the channel but also transferred the sediment particles to the centerline of the channel. Therefore, the minimum scouring depth was occurred at the center of the channel. In conclusion, the concave bed sill can be used to protect the upstream of the bed sill and it is also effective in stabilizing the centerline of the channel at the downstream of the bed sill.

Table 2. Percent of errors between experimental and simulation model.

\begin{tabular}{ll}
\hline Profile & Error (\%) \\
\hline A & 5.9 \\
B & 8.32 \\
C & 10.3 \\
\hline
\end{tabular}

Figure 11. Contour lines of Turbulent Kinetic energy from side view. 


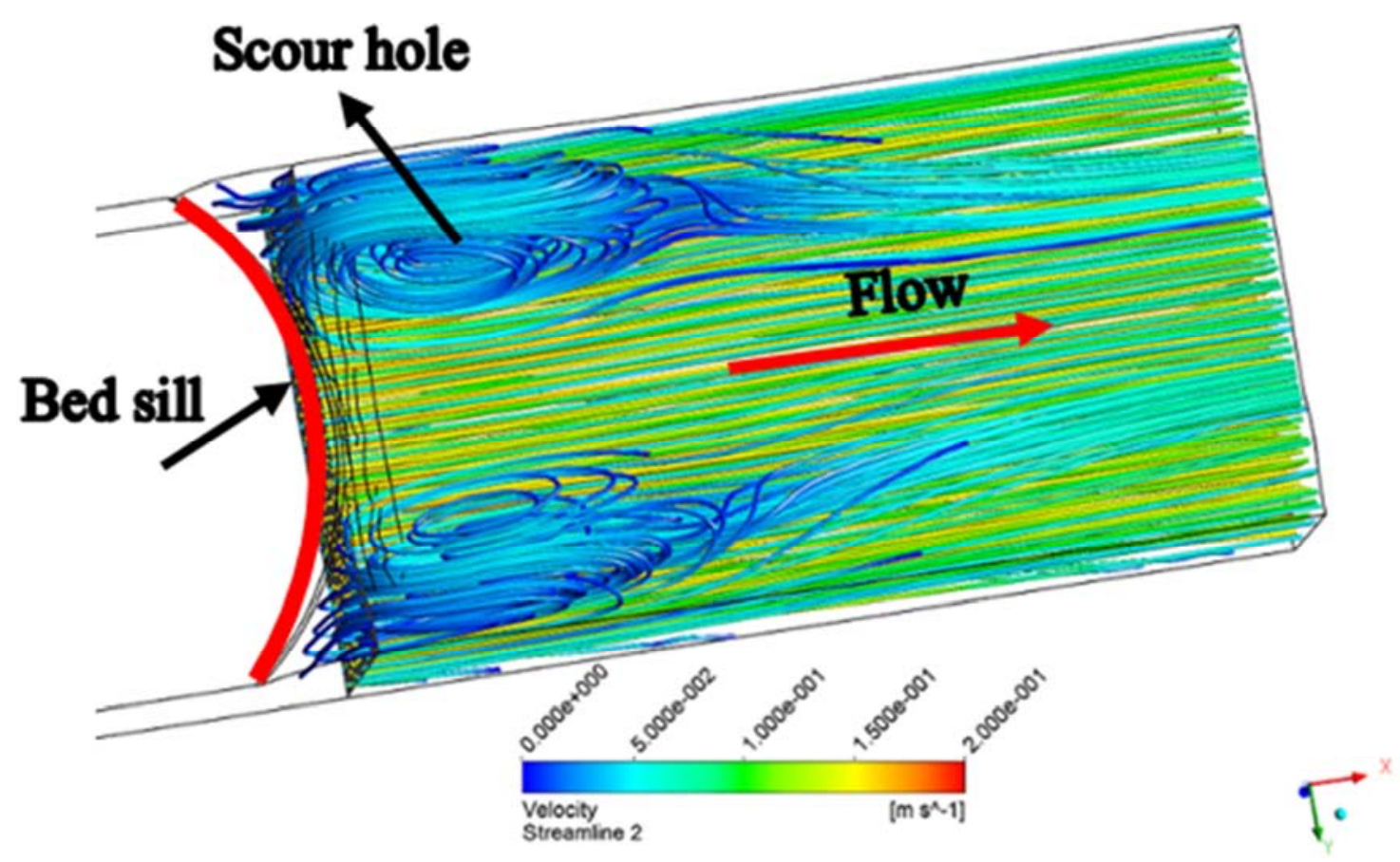

Figure 12. Velocity streamlines of simulated model.

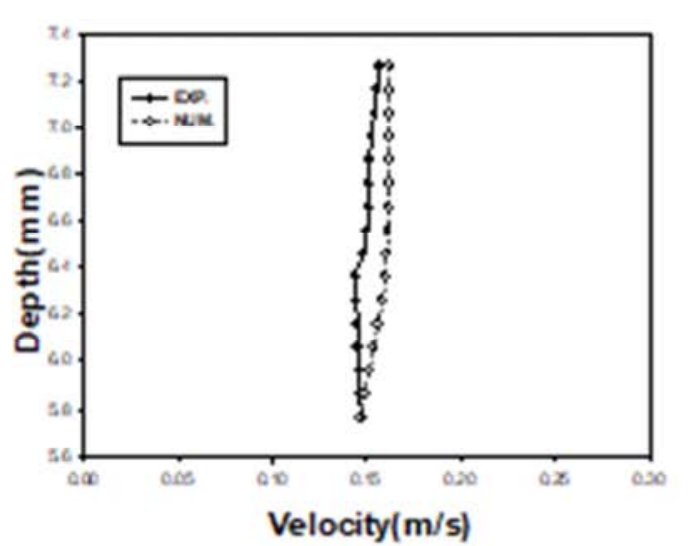

a) 0.05 from wall

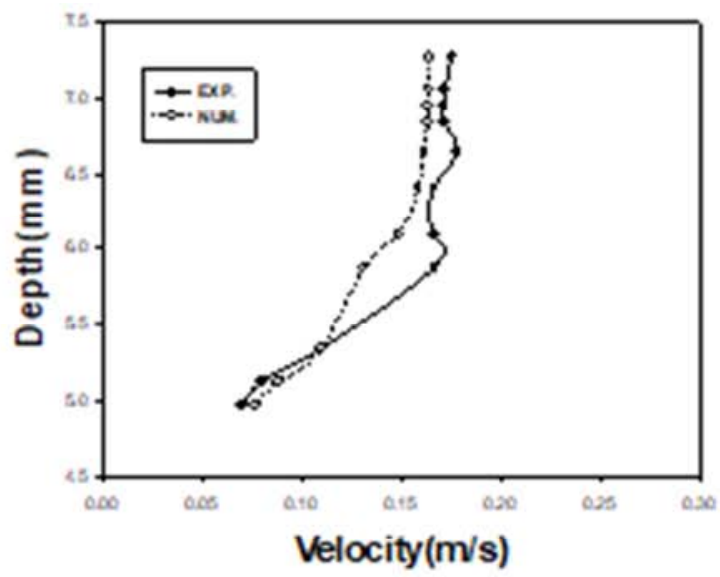

b) 0.10 from wall

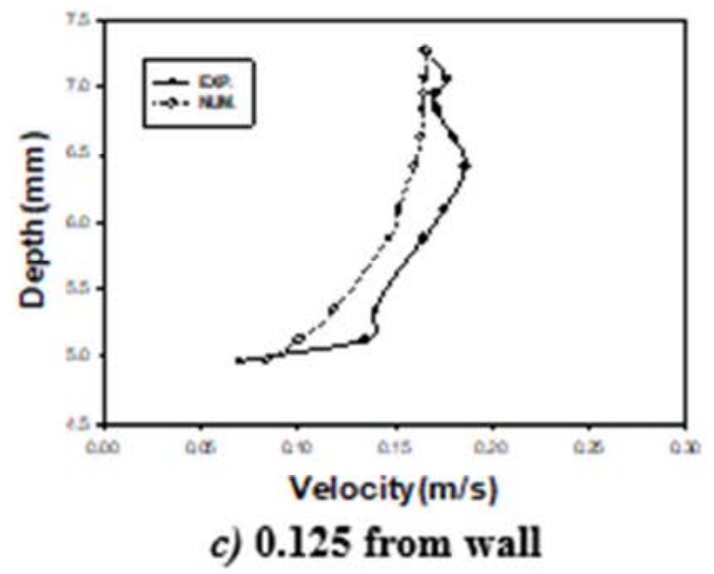

Figure 13. Comparison of experimental and simulated data of velocity in $x$-direction. 


\section{References}

[1] M. Ben Meftah and M. Mossa, "Experimental study of the scour hole downstream of bed sills," in River Flow, M. Greco, A. Carravetta and R. Della Morte Eds., pp. 585-592, 2004.

[2] C. Chinnarasri and D. Kositgittiwong, "Laboratory study of maximum scour depth downstream of sills," In Proceedings of the Institution of Civil Engineers-Water Management, vol. 161, no. 5, pp. 267-275, 2008.

[3] R. Gaudio and A. Marion, "Time evolution of scouring downstream of bed sills," Journal of Hydraulic Research, vol. 41, no. 3, pp. 271-284, 2003.

[4] R. Gaudio, A. Marion and V. Bovoli, "Morphological effects of bed sills in degrading rivers," Journal of Hydraulic Research, 38 (2), pp. 89-96, 2000.

[5] D. Guan, B. Melville, and H. Friedrich, "Flow patterns and turbulence structures in a scour hole downstream of a submerged weir," Journal of Hydraulic Engineering 140.1, pp. 68-76, 2014.

[6] D. Guan, B. Melville and H. Friedrich, "Local scour at submerged weirs in sand-bed channels," Journal of Hydraulic Research, vol. 54, no. 2, pp. 172-184, 2016.

[7] H. Hamidifar, M. Nasrabadi, and M. H. Omid, "Using a bed sill as a scour countermeasure downstream of an apron," Ain Shams Engineering Journal 9.4, pp. 1663-1669, 2018.

[8] H. Hamidifar, M. H. Omid, and M. Nasrabadi, "Reduction of scour using a combination of riprap and bed sill," Proceedings of the Institution of Civil Engineers-Water Management. Vol. 171. No. 5. Thomas Telford Ltd, 2018.

[9] A. Keshavarzi and L. Khaje Noori, "Environmental protection stability of river bed and banks using convex, concave, and linear bed sills," Environmental Monitoring and Assessment, vol. 17, no. 1, pp. 621-631, 2010.

[10] A. Keshavarzi and M. Sohrabi, "Study on the effect of different bed sills on flow structure and scouring at the bed of channel," Proceedings of the 3rd International Conference on Civil, Structural and Transportation Engineering (ICCSTE'18), Niagara Falls, Canada, June 10-12, 2018.

[11] A. Keshavarzi, R. Gazni, and R. Homayoon, "Prediction of scouring around an arch-shaped bed sill using neuro-fuzzy model," Applied Soft Computing, vol. 12, pp. 486-493, 2012.

[12] M. A. Lenzi, A., Marion, Comiti, F and R. Gaudio, "Local scouring in low and high gradient streams at bed sills," Journal of Hydraulic Research, IAHR, vol. 40, no. 6, pp. 731-739, 2002.

[13] J. Y. Lu, J. H. Hong, K. P. Chang, and T. F. Lu, "Evolution of scouring process downstream of grade-control structures under steady and unsteady flows," Hydrological Processes 27.19, pp. 2699-2709, 2013.

[14] M. Sohrabi, A. Keshavarzi, and M. Javan, "Impact of Bed Sill Shapes on Scour Protection in River Bed and Banks," International Journal of River Basin Management 17.3, pp. 277-287, 2018.

[15] M. Tregnaghi, "Local scouring at bed sills under steady and unsteady conditions," Ph. D. Thesis, University of Padova: 161, 2008.

[16] M. Tregnaghi, A. Marion, A. Bottacin-Busolin, and S. J. Tait, "Modelling time varying scouring at bed sills," Earth Surface Processes and Landforms 36.13, pp. 1761-1769, 2011. 